\title{
An Analysis on Causes for Failure in Mathematics by Engineering Students in Tamil Nadu using Combined Overlap Fuzzy Clustering Model (COFCLM)
}

\author{
A. Praveen Prakash \\ Department of Mathematics \\ Hindustan University \\ Padur, Chennai - 603103
}

\author{
M.P. Kannan \\ Department of Mathematics \\ Hindustan University \\ Padur, Chennai - 603103
}

\author{
J. Esther Jerlin \\ Department of Mathematics \\ Hindustan University \\ Padur, Chennai - 603103
}

\begin{abstract}
The main objective of this paper is to introduce a new fuzzy model called Combined Overlap Fuzzy Clustering Model (COFCLM). First time, the working rule for this model is derived by creating an algorithm. The quality of teaching and learning mathematics has been one of the major challenges and concern for the educators. Mathematics comprises of wide variety of skills and concepts. Mathematics education should enable engineering students to communicate their ideas in an unambiguous and understandable way and should equip themselves with the analytical skills as practicing engineers. Mathematical thinking and modelling give engineers the ability to approach new problems with confidence. There are around 570 engineering colleges in Tamil Nadu where most students show their aversion in learning mathematics and they learn this subject without involvement and interest. More number of arrears is kept in this subject compared to other subjects by students who are backward in studies. Students fail to understand the seriousness of this subject. This paper consists of seven sections. Section one is introductory in nature that gives the background of the problem under study and gives the justification for having chosen to use the "Combined Overlap Fuzzy Clustering Model (COFCLM)" approach to seek the dominant causes for the failure in Mathematics. Section two gives the preliminaries and the basics of Combined Overlap Fuzzy Clustering Model approach. Section three deals with the application of the said approach in determining the cluster of problems, that fall under the categories 'low', 'moderate' and 'high'. Section four gives the algorithm for the working of the model. Section five gives the main findings as conclusions. Section six deals with the suggestions for the study of the problem. And, the final seventh section gives the references used for the study.
\end{abstract}

\section{Keywords}

Clustering, Fuzzy Clustering, Combined Fuzzy Clustering, Combined Overlap Fuzzy Clustering Model (COFCLM), Degrees of Membership, Failure in Maths.

\section{INTRODUCTION}

\subsection{Existing Scenario}

An article published at "THE HINDU" on March 12th, 2012 clearly dealt with the sensational issue of engineering students failing in maths and in computing. In the very beginning of the academic itself most first year students lag behind in subjects especially in maths than in other subjects. The semester result of
Anna University revealed a worrying trend of it. Most students who failed have not been able to clear two subjects- mathematics and computing even after repeated attempts.

While Anna University recorded a pass percentage of 69, many self-financed colleges in the city have recorded just about 40-50 per cent pass result, with most students failing in mathematics and FoC (Fundamental of Computing) and some in engineering graphics. They quoted, various reasons for the failure in mathematics. The shortage of dedicated faculties to teach maths is one among the Major reasons.

An article on Jan 25, 2012 tells that the Mathematics I exam that was conducted on Monday was quite a difficult paper. "We didn't understand most of the questions. They were very complicated," says a student of S.S.N. College of Engineering. The 100-mark paper had questions on integration, matrices, differential equations, partial derivatives and $3 \mathrm{D}$ analytical geometry. "There are five compulsory units in the paper so that we don't omit any section. But the relatively easier ones were the 2 marks questions while the 8 mark ones were very difficult," says a student of Madras Institute of Technology.

But there was no conscious attempt to make the question paper difficult, said Anna University Vice-Chancellor Mannar Jawahar. Necessary moderation will be employed in case the questions were found difficult by the majority, or out of syllabus, he said. "The first year students are facing a process of transition in terms of teaching and learning methods that are different from school. Such testing methods will encourage teachers and students to not go for rote learning and practice problem solving," he added.

While admitting this is a serious and growing problem, teachers and students blame each other for such situations. Students say teachers avoid solving tough questions in classrooms, while teachers blame it on lack of time. "There are six subjects in a semester of three months. In barely 60 hours of teaching, we are expected to finish an extensive syllabus. Most students are not strong in the fundamentals of the subject and so it is impossible to start from scratch," said a lecturer who teaches mathematics to first-year students. "There are at least 20 students in the class who have scored a centum in their class XII maths exam, but only about three of them secured above 70 per cent in the mathematics exam here. Many have failed too," she added.

N. Balachandran, former professor, Anna University, says the inability of engineering students to cope with mathematics in the college curriculum has always existed but has worsened over the years. 
"Engineering mathematics has to do with application. Most students are not ready for that because the way they approach mathematics in school is very text-book and examination oriented. That does not work in college," he said. "Students seldom take an interest in mathematics. Few go to the library, borrow books and try out sums on their own. For most, it is a subject to be done away with as soon as possible," he added. Referred at THE HINDU article - February 4th, 2013. As the number of engineering colleges had grown in number from just 15 in 1984 to 570 in 2014, the quality of the students at entry level are given a scant respect. Any parent who wished their children to become engineers get admission by paying donation. The interest and attitude of students are not assessed and taken into account for admitting them in engineering course. Even after all then, over one lakh seats were left vacant in engineering colleges in Tamil Nadu in 2013-2014.

\subsection{Objective of the Study}

To find out the dominate causes for engineering students failing in Mathematics in Tamil Nadu.

\subsection{Methodology}

The causes for failures in mathematics among students studying Engineering courses in colleges are categorized as fifteen attributes by interviewing and collecting the data from engineering students, engineering faculties, and parents of engineering students and the members of Institution at Chennai. The following fifteen attributes obtained from them are listed below. COFCLM is used to find out the dominant causes for the problem.

$\mathrm{C}_{1}$. Take the Engineering courses due to parent's compulsion

$\mathrm{C}_{2}$ - Faculties are not dedicated to their teaching Profession

$\mathrm{C}_{3}$ - Harsh approach of the engineering maths faculties

$\mathrm{C}_{4}$ - Students irregular to the class

$\mathrm{C}_{5}$ - Lack in thorough knowledge of basics taught in XI and XII std maths syllabus

$\mathrm{C}_{6}$ - Lack of logical reasoning and application skill by the students

$\mathrm{C}_{7}$ - Institution fails to provide good atmosphere for the teacher - student relation to flourish

$\mathrm{C}_{8}$ - Providing notes as study materials instead of teaching

$\mathrm{C}_{9}$ - Loss of memory by the students

$\mathrm{C}_{10}$ - Loss of attention by the students

$\mathrm{C}_{11}$-Lack of sufficient practice by the students

$\mathrm{C}_{12}$-Considering maths as difficult subject and having fear for it from the childhood

$\mathrm{C}_{13}$ - Lack of problem solving skill

$\mathrm{C}_{14}$ - Attitude of students to enjoy the college life with peer group and considering to keep arrear as fashion

$\mathrm{C}_{15}$ - Problem of language in understanding mathematical terms
Fuzzy c- means clustering is done using (4.1) to classify the above 15 attributes into three clusters viz low, moderate and high.

\section{PRELIMINARIES}

\subsection{Hard Clustering}

In Hard Clustering the data set $\mathrm{Z}$ is divided into hard partitions, (i.e) the partitions are made into $c \geq 2$ clusters, which means

$\bigcup_{i=1}^{c} A_{i}=Z$

and $A_{i} \cap A_{j}=\phi, \forall \mathrm{i} \neq \mathrm{j}$

With the condition that none of the sets, Ai should be empty. The usage of membership functions $\mu_{\mathrm{k}}(\mathrm{x})$ is applied to indicate partitioning. If $\mu_{\mathrm{k}}(\mathrm{x})=1$, then object $\mathrm{x}$ belongs to the cluster $\mathrm{k}$. Depending on the membership functions, the Partition Matrix $U$ is assembled, of which $\mu_{\mathrm{k}}(\mathrm{x})$ are the elements. Finally, there is a rule that $\forall \mathrm{x}$,

$\left.\sum_{i=1}^{c}\right\}_{k}(x)=1 \quad \forall x$

In other words, every object lies in only one part of the cluster.

\subsection{Fuzzy Clustering}

When an object belongs to both clusters $A_{i}$ and $A_{j}$, it should belong to any one of these clusters. Also, outliers have to be put in some cluster. This is unacceptable in hard clustering. But it can be overcome by fuzzy clustering.

In Fuzzy clustering, the data is Fuzzy partitioned, (i.e) the membership function $\mu_{\mathrm{k}}(\mathrm{x})$ takes the value between 0 and 1 . This means that an object $\mathrm{z}_{\mathrm{k}}$ can be for 0.3 parts in $\mathrm{A}_{\mathrm{i}}$ and for 0.7 parts in $A_{j}$. However, requirement (2) is satisfied. Hence, the sum of the membership functions remains to be $1 . \mathrm{M}_{\mathrm{fc}}$ denotes the set of all fuzzy partitions that can be formed in this manner. Fuzzy partitioning again has its drawback that when an outlier in the data (being an object that doesn"t really belong to any cluster), but still has to be assigned to the clusters. That is, the sum of its membership functions still must be equal to one. [5], [9]

\subsection{Fuzzy C-Means Clustering}

In fuzzy clustering, each point has a degree of belonging to clusters, as in fuzzy logic, rather than belonging completely to just one cluster. Thus, points on the edge of a cluster, may be in a cluster to a lesser degree than points in the center of cluster for each point $\mathrm{x}$ there is no coefficient giving the degree of belonging in the $\mathrm{k}^{\text {th }}$ cluster $\mu_{\mathrm{k}}(\mathrm{x})=1$. Usually, the sum of those coefficients is defined to be 1 . [8], [1].

$\sum_{n=1}$ mn cluster ${ }_{k}=1 \forall x$

With fuzzy c-means, the centroid of a cluster is the mean of all points, weighted by their degree of belonging to the cluster

Center $_{k}=\frac{\sum_{x} \square_{k}(x)^{m} x}{\sum_{x} \mathbb{Q}_{k}(x)^{m}}$

The degree of belonging is related to the inverse of the distance to the cluster

]$_{k}(x)=\frac{1}{d\left(\text { Center }_{k}, x\right)}$ 
Then the coefficients are normalized and fuzzy field with a real parameter $m>1$ so that their sum is 1 . So

$$
\square_{k}(x)=\frac{1}{\sum_{j}\left(\frac{\text { Center }_{k}, x}{\text { Center }_{j}, x}\right)^{2 /(m-1)}} .
$$

For $m$ equal to 2, this is equivalent to normalizing the coefficient linearly to make their sum 1 . When $\mathrm{m}$ is close to 1 , then cluster center closes to the point is given much more weight than the others, and the algorithm is similar to $k$-means.

\subsection{Combined Fuzzy Clustering}

Finite number of Fuzzy Clustering can be combined to produce joint effect of all the Fuzzy clustering. Let Table 1, Table 2,..., Table $n$ be the table of degree of membership of the attributes of $n$ experts, then the combined Fuzzy Clustering is obtained by adding the corresponding membership value of each attribute. [7], [4], [6]

\subsection{Combined Overlap Fuzzy Clustering Model (COFCLM):}

Let $C_{1}, C_{2} \ldots, C_{n}$ be $n$ distinct attributes of a problem $n$ very large. We divide these $\mathrm{n}$ attributes into $\mathrm{k}$ classes where the attributes overlap each other in classes and these $\mathrm{k}$ equal classes are viewed by k-experts or by the same expert and the corresponding degree of membership is given to the attributes. [10], [4], [6]

\section{RESULTS AND DISCUSSION}

100 engineering students, engineering faculties and parents of engineering students in Chennai were interviewed to find the causes for the failure in mathematics. The fifteen attributes have been chosen and the respondents have rated the attributes of problems based on their opinion. The following figures and table shows the result of our analysis. The analysis is carried on a 10point rating scale.

The ratings and the Standard Deviation of the attributes for the causes of failures in mathematics by engineering students have been subjected to fuzzy c-means clustering using algorithm (4.1) and the following results are shown in Table 2, Table 3, Table 4, Table 5, Table 6 and Table 7 according to the expert's opinion. The following tables are obtained for a 3-cluster combination.

The first cluster comprises of the attributes with average rating from 2 to 5 with a mid-value 3.5. The second cluster range is from 3 to 8 with a mid-value 5.5 and the third cluster has a range of $7-10$ with a mid-value 8.5 .

The first, second and third clusters range indicates the causes of failures in mathematics by engineering students showing the low, moderate and high level of the causes. There is over-lapping ranges as in characteristic of a fuzzy based cluster.

For the same, 3-cluster Range of level of Dominant Cause (i.e)

Table 1. 3-cluster Range of level of Dominant Cause

\begin{tabular}{|l|l|l|l|}
\hline & Cluster 1 & Cluster 2 & Cluster 3 \\
\hline Range & $2.0-5.0$ & $3.0-8.0$ & $7.0-10$ \\
\hline Mid Value & 3.5 & 5.5 & 8.5 \\
\hline Classification & LOW & MEDIUM & HIGH \\
\hline
\end{tabular}

The fifteen attributes are divided into six overlapping blocks

$$
\begin{aligned}
& \mathrm{T}_{1}=\left\{\mathrm{C}_{12}, \mathrm{C}_{9}, \mathrm{C}_{11}, \mathrm{C}_{1}, \mathrm{C}_{14}\right\} \\
& \mathrm{T}_{2}=\left\{\mathrm{C}_{13}, \mathrm{C}_{10}, \mathrm{C}_{3}, \mathrm{C}_{2}, \mathrm{C}_{4}\right\} \\
& \mathrm{T}_{3}=\left\{\mathrm{C}_{6}, \mathrm{C}_{5}, \mathrm{C}_{7}, \mathrm{C}_{8}, \mathrm{C}_{15}\right\} \\
& \mathrm{T}_{4}=\left\{\mathrm{C}_{2}, \mathrm{C}_{3}, \mathrm{C}_{4}, \mathrm{C}_{14}, \mathrm{C}_{1}\right\} \\
& \mathrm{T}_{5}=\left\{\mathrm{C}_{15}, \mathrm{C}_{12}, \mathrm{C}_{9}, \mathrm{C}_{5}, \mathrm{C}_{6}\right\} \\
& \mathrm{T}_{6}=\left\{\mathrm{C}_{7}, \mathrm{C}_{8}, \mathrm{C}_{10}, \mathrm{C}_{11}, \mathrm{C}_{13}\right\}
\end{aligned}
$$

The mean rating of the dominant cause for each class is given by the experts

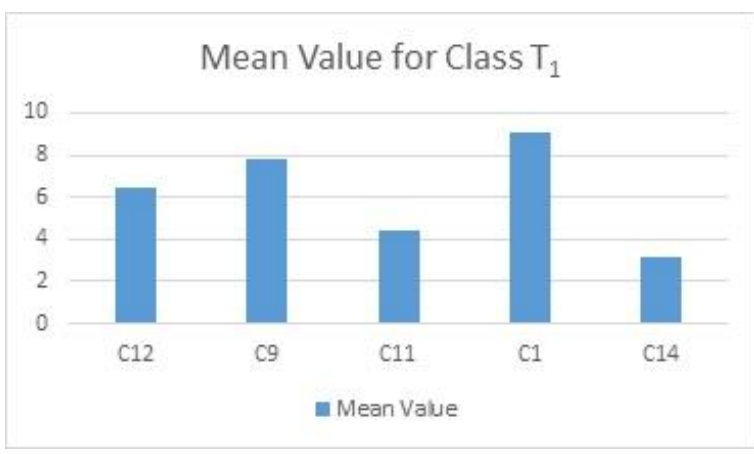

Fig 1: Mean Value for Class $T_{1}$

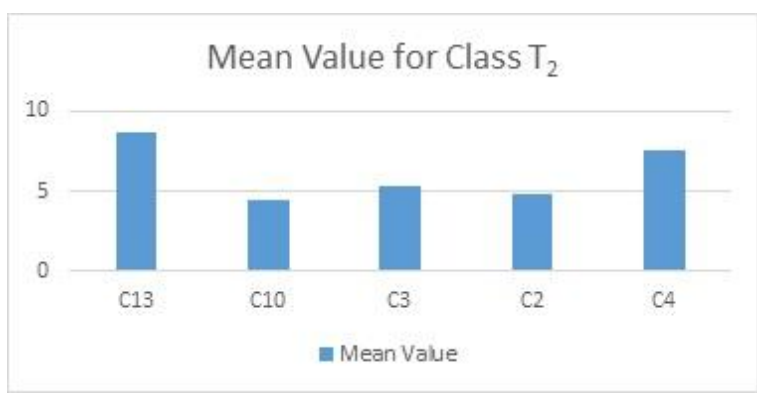

Fig 2: Mean Value for Class $\mathbf{T}_{2}$

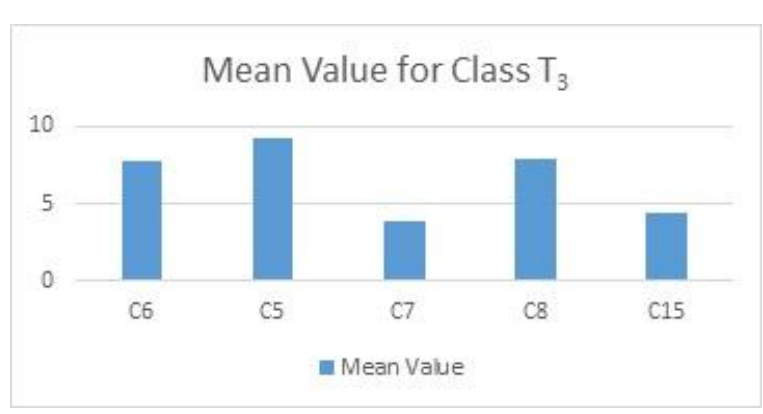

Fig 3: Mean Value for Class $\mathbf{T}_{3}$ 


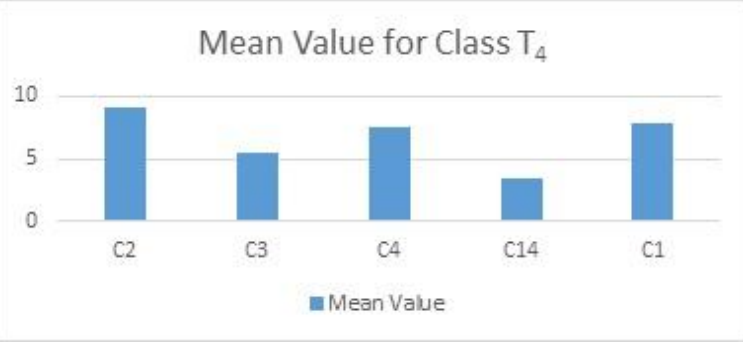

Fig 4: Mean Value for Class $\mathbf{T}_{4}$

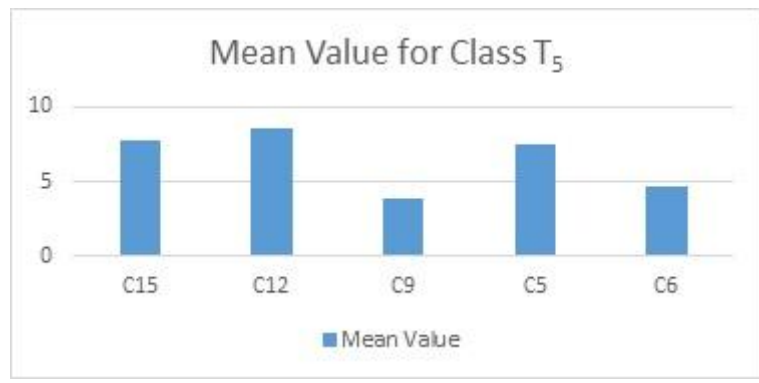

Fig 5: Mean Value for Class $\mathbf{T}_{5}$

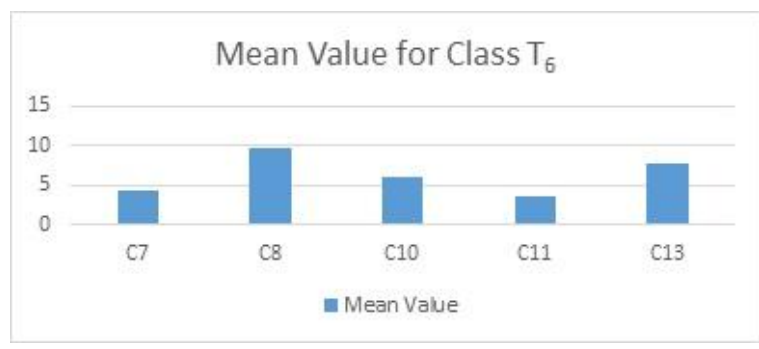

Fig 6: Mean Value for Class $T_{6}$

\section{ALGORITHM}

\subsection{Algorithm to find a Membership Values for the Attributes}

STEP 1: Start

STEP 2: Fix, the values of 15 attributes on a 10-point rating scale in a set D (say)

STEP 3: Fix the cluster, which is defined as Cluster $1=$ LOW, whose range beginning with 2 (bv1) End with 5 (ev1). Cluster $2=$ MODERATE, whose range beginning with 3 (bv2) end with 8 (ev2). Cluster $3=\mathrm{HIGH}$, whose range beginning with 7 (bv3) end with 10 (ev3).

STEP 4: Choose an element $x$ in D

STEP 5: If $x$ < ev1, Go to STEP 6, else Go to STEP 8
STEP 6: If $x>b v 2$, then $x$ lies in cluster 1 and cluster 2 whose membership value is defined as $\boldsymbol{\mu}_{\mathbf{k}}(\boldsymbol{x})=\mathbf{e v 1 - x}: \boldsymbol{x}-\mathbf{b v 2}$, Go to STEP 12, else Go to STEP 7.

STEP7: Then $\boldsymbol{x}$ lies in cluster 1 only, the membership value is $\mu_{\mathrm{k}}(x)=1$ Go toSTEP 12

STEP 8: If $x<\mathrm{ev} 2$ Go to STEP 9, else Go to STEP 11

STEP 9: If $x>$ bv3, then $x$ lies in cluster 2 and cluster 3, whose membership value is defined as $\boldsymbol{\mu}_{\mathbf{k}}(\boldsymbol{x})=\mathbf{e v} \mathbf{2}-\boldsymbol{x}: \boldsymbol{x}$-bv3, Go to step 12, else Go to STEP10

STEP 10: Then $x$ lies in cluster 2 only, the membership value is $\mu_{\mathbf{k}}(x)=1$ else Go to_STEP11

STEP 11: Then $x$ lies in cluster 3 only, the membership value is $\boldsymbol{\mu}_{\mathbf{k}}(\boldsymbol{x})=\mathbf{1}$

STEP 12: Go to STEP 4, until all the values in D have been checked

STEP 13: Stop

Here 'bv' denotes the beginning value and ev' denotes the ending the value. [5], [9].

\subsection{Algorithm to find a Membership Values for the Attributes Combined Overlap Fuzzy Clustering Model}

STEP 1: Start

STEP 2: $\mathbf{X}=\left(\mathrm{X}_{1}+\mathrm{X}_{2}+\ldots+\mathrm{X}_{\mathrm{N}}\right) / \mathrm{N}$, from the corresponding rows of Tables. GOTO STEP 3.

STEP 3: $\mathbf{L}=\left(\mathrm{L}_{1}+\mathrm{L}_{2}+\ldots+\mathrm{L}_{\mathrm{N}}\right) / \mathrm{N}$, from the corresponding rows of Tables. GOTO STEP 4.

STEP 4: $\quad \mathbf{M}=\left(\mathrm{M}_{1}+\mathrm{M}_{2}+\ldots+\mathrm{M}_{\mathrm{N}}\right) / \mathrm{N}$, from the corresponding rows of Tables. GOTO STEP 5.

STEP 5: $\quad \mathbf{H}=\left(\mathrm{H}_{1}+\mathrm{H}_{2}+\ldots+\mathrm{H}_{\mathrm{N}}\right) / \mathrm{N}$, from the corresponding rows of Tables. GOTO STEP 6.

STEP 6: if $(\mathbf{L}<=\mathbf{M})$ and if $(\mathbf{M}<=\mathbf{H})$, put $\mathrm{H}=1$ else $\mathrm{M}=1$, else GOTO STEP 7.

STEP7: if $(\mathbf{L}<=\mathbf{H})$ put $\mathrm{H}=1$ else $\mathrm{L}=1$. GOTO STEP 8 .

STEP 8: GOTO STEP 2 until attaining all the membership value for the corresponding rows. GOTO STEP 9.

STEP 9: Stop

Here ' $\mathbf{X}$ ' denotes the Mean Value, ' $\mathbf{L}$ ' denotes the LOW, ' $\mathbf{M}$ ' denotes the Moderate and ' $\mathbf{H}$ ' denotes the High.

The following tables gives the degree of membership of the attributes of each class

Table 2. For class $T_{1}$

\begin{tabular}{|l|l|l|l|l|}
\hline Attributes & Mean & Low & Moderate & High \\
\hline $\mathrm{C}_{12}$ & 6.5 & 0 & 1 & 0 \\
\hline $\mathrm{C}_{9}$ & 7.8 & 0 & 0.2 & 0.8 \\
\hline $\mathrm{C}_{11}$ & 4.4 & 0.3 & 0.7 & 0 \\
\hline $\mathrm{C}_{1}$ & 9.1 & 0 & 0 & 1 \\
\hline $\mathrm{C}_{14}$ & 3.2 & 0.9 & 0.1 & 0 \\
\hline
\end{tabular}


According to the expert view, degree of membership of the attributes that refer to the causes of failure in mathematics by engineering students is found using the above algorithm and shown in Table 2. Attributes $\mathrm{C}_{12}$ with a mean rating 6.5 is entirely $(100 \%)$ with a membership value of 1 in cluster 2 . (i.e.) MODERATE.

Attribute $\mathrm{C}_{1}$ with a mean rating 9.1 is entirely (100\%) with a membership value of 1 in cluster 3. (i.e.) HIGH.

Attributes $\mathrm{C}_{11}$ and $\mathrm{C}_{14}$ with a mean ratings $4.4,3.2$ belongs to $30 \%$ in cluster 1 and $70 \%$ in cluster $2,90 \%$ in cluster 1 and $10 \%$ in cluster 2, (i.e.) between LOW and MODERATE.

Attributes $\mathrm{C}_{9}$ with a mean ratings 7.8 belongs to $20 \%$ in cluster 2 and $80 \%$ in cluster 3 (i.e.) between MODERATE and HIGH.

Table 3. For class $\mathbf{T}_{2}$

\begin{tabular}{|l|l|l|l|l|}
\hline Attributes & Mean & Low & Moderate & High \\
\hline$C_{13}$ & 8.7 & 0 & 0 & 1 \\
\hline$C_{10}$ & 4.8 & 0.3 & 0.7 & 0 \\
\hline$C_{3}$ & 5.3 & 0 & 1 & 0 \\
\hline$C_{2}$ & 7.9 & 0.1 & 0.9 & 0 \\
\hline$C_{4}$ & 7.6 & 0 & 0.4 & 0.6 \\
\hline
\end{tabular}

According to the expert view, degree of membership of the attributes that refer to the causes of failure in mathematics by engineering students is found using the above algorithm and shown in Table 3. Attributes $\mathrm{C}_{3}$ with a mean rating 5.3 is entirely $(100 \%)$ with a membership value of 1 in cluster 2 . (i.e.) MODERATE.

Attribute $\mathrm{C}_{13}$ with a mean rating 8.7 is entirely (100\%) with a membership value of 1 in cluster 3. (i.e.) HIGH.

Attributes $\mathrm{C}_{10}$ and $\mathrm{C}_{2}$ with a mean ratings $4.4,4.8$ belongs to $30 \%$ in cluster 1 and $70 \%$ in cluster $2,10 \%$ in cluster 1 and 90\% in cluster 2, (i.e.) between LOW and MODERATE.

Attributes $\mathrm{C}_{4}$ with a mean ratings 7.6 belongs to $40 \%$ in cluster 2 and $60 \%$ in cluster 3 (i.e.) between MODERATE and HIGH.

Table 4. For class $T_{3}$

\begin{tabular}{|l|l|l|l|l|}
\hline Attributes & Mean & Low & Moderate & High \\
\hline$C_{6}$ & 7.7 & 0 & 0.3 & 0.7 \\
\hline$C_{5}$ & 9.3 & 0 & 0 & 1 \\
\hline$C_{7}$ & 3.8 & 0.6 & 0.4 & 0 \\
\hline$C_{8}$ & 7.9 & 0 & 0.1 & 0.9 \\
\hline$C_{15}$ & 4.4 & 0.3 & 0.7 & 0 \\
\hline
\end{tabular}

According to the expert view, degree of membership of the attributes that refer to the causes of failure in mathematics by engineering students is found using the above algorithm and shown in Table 4. Attribute $\mathrm{C}_{5}$ with a mean rating 9.3 is entirely $(100 \%)$ with a membership value of 1 in cluster 3 . (i.e.) HIGH.

Attributes $\mathrm{C}_{7}$ and $\mathrm{C}_{15}$ with a mean ratings $3.8,4.4$ belongs to $60 \%$ in cluster 1 and $40 \%$ in cluster $2,30 \%$ in cluster 1 and $70 \%$ in cluster 2, (i.e.) between LOW and MODERATE.
Attributes $\mathrm{C}_{6} \mathrm{C}_{8}$ with a mean ratings 7.7, 7.9 belongs to $30 \%$ in cluster 2 and $70 \%$ in cluster 3,10\% in cluster 2 and $90 \%$ in cluster 3 (i.e.) between MODERATE and HIGH.

Table 5: For class $T_{4}$

\begin{tabular}{|l|l|l|l|l|}
\hline Attributes & Mean & Low & Moderate & High \\
\hline$C_{2}$ & 9.1 & 0 & 0 & 1 \\
\hline$C_{3}$ & 5.5 & 0 & 1 & 0 \\
\hline$C_{4}$ & 7.5 & 0 & 0.5 & 0.5 \\
\hline$C_{14}$ & 3.4 & 0.8 & 0.2 & 0 \\
\hline$C_{1}$ & 7.9 & 0 & 0.1 & 0.9 \\
\hline
\end{tabular}

According to the expert view, degree of membership of the attributes that refer to the causes of failure in mathematics by engineering students is found using the above algorithm and shown in Table 5. Attributes $\mathrm{C}_{3}$ with a mean rating 5.5 is entirely $(100 \%)$ with a membership value of 1 in cluster 2 . (i.e.) MODERATE.

Attribute $\mathrm{C}_{2}$ with a mean rating 9.1 is entirely (100\%) with a membership value of 1 in cluster 3. (i.e.) HIGH.

Attributes $\mathrm{C}_{14}$ with a mean ratings 3.4 belongs to $80 \%$ in cluster 1 and $20 \%$ in cluster 2 (i.e.) between LOW and MODERATE.

Attributes $\mathrm{C}_{4}$ and $\mathrm{C} 1$ with a mean ratings $7.5,7.9$ belongs to $50 \%$ in cluster 2 and $50 \%$ in cluster 3,10\% in cluster 2 and $90 \%$ in cluster 3 (i.e.) between MODERATE and HIGH.

Table 6: For class $T_{5}$

\begin{tabular}{|l|l|l|l|l|}
\hline Attributes & Mean & Low & Moderate & High \\
\hline $\mathrm{C}_{15}$ & 7.7 & 0 & 0.3 & 0.7 \\
\hline $\mathrm{C}_{12}$ & 8.6 & 0 & 0 & 1 \\
\hline $\mathrm{C}_{9}$ & 3.8 & 0.6 & 0.4 & 0 \\
\hline $\mathrm{C}_{5}$ & 7.5 & 0 & 0.5 & 0.5 \\
\hline $\mathrm{C}_{6}$ & 4.6 & 0.2 & 0.8 & 0 \\
\hline
\end{tabular}

According to the expert view, degree of membership of the attributes that refer to the causes of failure in mathematics by engineering students is found using the above algorithm and shown in Table 6. Attribute $\mathrm{C}_{12}$ with a mean rating 8.6 is entirely $(100 \%)$ with a membership value of 1 in cluster 3. (i.e.) HIGH.

Attributes $\mathrm{C}_{9}$ and $\mathrm{C}_{6}$ with a mean ratings $3.8,4.6$ belongs to 60 $\%$ in cluster 1 and $40 \%$ in cluster $2,20 \%$ in cluster 1 and $80 \%$ in cluster 2 (i.e.) between LOW and MODERATE.

Attributes $\mathrm{C}_{15}$ and $\mathrm{C}_{5}$ with a mean ratings $7.7,7.5$ belongs to 30 $\%$ in cluster 2 and $70 \%$ in cluster $3,50 \%$ in cluster 2 and $50 \%$ in cluster 3 (i.e.) between MODERATE and HIGH. 
Table 7: For class $\mathbf{T}_{6}$

\begin{tabular}{|l|l|l|l|l|}
\hline Attributes & Mean & Low & Moderate & High \\
\hline$C_{7}$ & 4.2 & 0.4 & 0.6 & 0 \\
\hline$C_{8}$ & 9.7 & 0 & 0 & 1 \\
\hline$C_{10}$ & 6.1 & 0 & 1 & 0 \\
\hline$C_{11}$ & 3.6 & 0.7 & 0.3 & 0 \\
\hline$C_{13}$ & 7.7 & 0 & 0.3 & 0.7 \\
\hline
\end{tabular}

According to the expert view, degree of membership of the attributes that refer to the causes of failure in mathematics by engineering students is found using the above algorithm and shown in Table 7. Attributes $\mathrm{C}_{10}$ with a mean rating 6.1 is entirely (100\%) with a membership value of 1 in cluster 2. (i.e.) MODERATE.

Attribute $\mathrm{C}_{8}$ with a mean rating 9.7 is entirely (100\%) with a membership value of 1 in cluster 3. (i.e.) HIGH.

Attributes $\mathrm{C}_{7}$ and $\mathrm{C}_{11}$ with a mean ratings $4.2,3.6$ belongs to 40 $\%$ in cluster 1 and $60 \%$ in cluster $2,70 \%$ in cluster 1 and $30 \%$ in cluster 2 (i.e.) between LOW and MODERATE.

Attributes $\mathrm{C}_{13}$ with a mean ratings 7.7 belongs to $30 \%$ in cluster 2 and $70 \%$ in cluster 3 (i.e.) between MODERATE and HIGH.

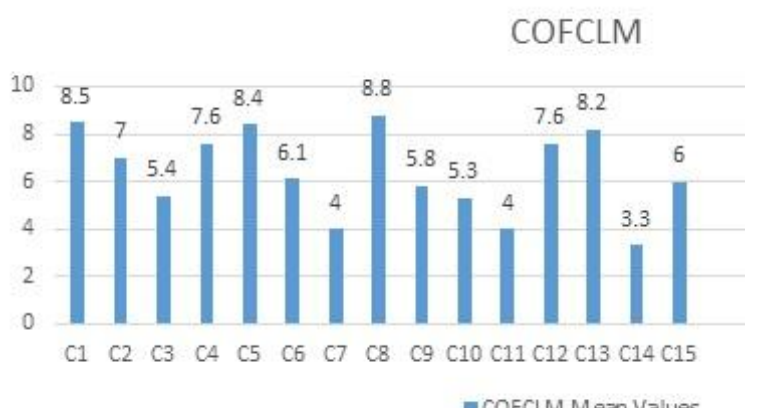

Fig 7: Mean rating of the Dominant cause- Combined Fuzzy Clustering Model (COFCLM)

Combined degree of membership of the attributes that refer to the causes of failure in mathematics by engineering students is found using the above algorithm is shown in Table 8 and then thresholded and updated to obtain the on state and off state of the attributes among the three level of classifications, Low, Moderate and High.
Table 8. COFCLM Degree of Membership of the attributes Combined Fuzzy Clustering Model

\begin{tabular}{|l|l|l|l|l|l|l|l|l|}
\hline Attributes & Mean & Low & Moderate & High & $\longrightarrow$ & Low & Moderate & High \\
\hline $\mathrm{C}_{1}$ & 8.5 & 0 & 0.05 & 0.95 & $\longrightarrow$ & 0 & 0 & 1 \\
\hline $\mathrm{C}_{2}$ & 7.0 & 0.05 & 0.45 & 0.5 & $\longrightarrow$ & 0 & 0 & 1 \\
\hline $\mathrm{C}_{3}$ & 5.4 & 0 & 1 & 0 & $\longrightarrow$ & 0 & 1 & 0 \\
\hline $\mathrm{C}_{4}$ & 7.6 & 0 & 0.45 & 0.55 & $\longrightarrow$ & 0 & 0 & 1 \\
\hline $\mathrm{C}_{5}$ & 8.4 & 0 & 0.25 & 0.75 & $\longrightarrow$ & 0 & 0 & 1 \\
\hline $\mathrm{C}_{6}$ & 6.1 & 0.1 & 0.55 & 0.35 & $\rightarrow$ & 0 & 1 & 0 \\
\hline $\mathrm{C}_{7}$ & 4 & 0.5 & 0.5 & 0 & $\longrightarrow$ & 0 & 1 & 0 \\
\hline $\mathrm{C}_{8}$ & 8.8 & 0 & 0.05 & 0.95 & $\longrightarrow$ & 0 & 0 & 1 \\
\hline $\mathrm{C}_{9}$ & 5.8 & 0.3 & 0.3 & 0.4 & $\longrightarrow$ & 0 & 0 & 1 \\
\hline $\mathrm{C}_{10}$ & 5.3 & 0.15 & 0.85 & 0 & $\longrightarrow$ & 0 & 1 & 0 \\
\hline $\mathrm{C}_{11}$ & 4 & 0.5 & 0.5 & 0 & $\longrightarrow$ & 0 & 1 & 0 \\
\hline $\mathrm{C}_{12}$ & 7.6 & 0 & 0.5 & 0.5 & $\longrightarrow$ & 0 & 0 & 1 \\
\hline $\mathrm{C}_{13}$ & 8.2 & 0 & 0.15 & 0.85 & $\longrightarrow$ & 0 & 0 & 1 \\
\hline $\mathrm{C}_{14}$ & 3.3 & 0.85 & 0.15 & 0 & $\longrightarrow$ & 1 & 0 & 0 \\
\hline $\mathrm{C}_{15}$ & 6.0 & 0.15 & 0.5 & 0.35 & $\longrightarrow$ & 0 & 0 & 1 \\
\hline
\end{tabular}

On analysis attributes $\mathrm{C}_{14}$ with a mean rating 3.3 come to the 'on state' in cluster 1. (i.e.) LOW level.

Attributes $\mathrm{C}_{3}, \mathrm{C}_{6}, \mathrm{C}_{7}, \mathrm{C}_{10}$ and $\mathrm{C}_{11}$ with a mean rating 5.4, 6.1, 4, 5.3, and 4 come to the 'on state' in cluster 2. (i.e.) MODERATE level.

Attribute $\mathrm{C}_{1}, \mathrm{C}_{2}, \mathrm{C}_{4}, \mathrm{C}_{5}, \mathrm{C}_{8}, \mathrm{C}_{9}, \mathrm{C}_{12}, \mathrm{C}_{13}$ and $\mathrm{C}_{15}$ with a mean rating 8.5, 7.0, 7.6, 8.4, 8.8, 5.8, 7.6, 8.2, 6.0 come to the 'on state' in cluster 3. (i.e.) HIGH level.

\section{CONCLUSION}

The Combined Overlap Fuzzy Clustering analysis highlights that among fifteen attributes taken for analysis by the collective opinion from Engineering students, Engineering faculties and parents of engineering students we arrived the attributes $\mathrm{C}_{1}, \mathrm{C}_{2}$, $\mathrm{C}_{4}, \mathrm{C}_{5}, \mathrm{C}_{8}, \mathrm{C}_{9}, \mathrm{C}_{12}, \mathrm{C}_{13}$ and $\mathrm{C}_{15}$ (i.e)

$\mathrm{C}_{1}$. Take the Engineering courses due to parent's compulsion

$\mathrm{C}_{2}$ - Faculties are not dedicated to their teaching Profession

$\mathrm{C}_{4}$ - Students irregular to the class

$\mathrm{C}_{5}$ - Lack in thorough knowledge of basics taught in XI and XII std maths syllabus

$\mathrm{C}_{8}$ - Providing notes as study materials instead of teaching

$\mathrm{C}_{9}$ - Loss of memory by the students

$\mathrm{C}_{12}$ - Considering maths as difficult subject and having fear for it from the childhood

$\mathrm{C}_{13}$ - Lack of problem solving skill

$\mathrm{C}_{15}$ - Problem of language in understanding mathematical terms

are the major causes for the failures in mathematics by engineering students. These attributes resulted in on state after thresholding and updating in the high level of classification.

\section{SUGGESTION}

Steps should be taken to conduct orientation for the Mathematics faculty members of all engineering colleges in Tamil Nadu before they begin their academic. According to the feedback from students, many schools do not teach important Mathematical subjects like Differentiation and Integration which was covered in Plus-1 syllabus. To ensure that students and faculty members 
should take some extra course seriously to learn. Worried over the high failure rate among engineering students in Mathematics, Anna University has decided to conduct a bridge course, compulsory for the $1^{\text {st }}$ year students. Certain other measures should also be taken in such a manner to reduce this problem.

\section{REFERENCES}

[1] B. Kosko, "Neural Networks and Fuzzy systems: A Dynamical System Approach to Machine Intelligence", Prentice Hall of India, 1997.

[2] H.J. Zimmermann, "Fuzzy Set Theory and its application”, Fourth Edition Springer 2011.

[3] J. Klir George/Bo Yuan, "Fuzzy sets and Fuzzy Logic: Theory and Applications", Prentice Hall of India.

[4] Vasantha Kandasamy W.B, Smarandache Florentin and K.Ilanthendral, "Elementary Fuzzy Matrix Theory and Fuzzy Models for Social Scientists"-2007.
[5] A.Victor Devadoss, A.Felix, "Fuzzy Clustering of the Domestic Violence for the Degree of Suicide thought based on Married Women Perception",2012, IJERA p: 1770-1773.

[6] Vasantha Kandasamy W.B and Smarandache Florentin "Fuzzy Cognitive Maps and Neutrosophic Cognitive Maps", Xiquan, Phoenix (2003).

[7] W.B.VasanthaKandasamy and S.Uma, "Combined Fuzzy Cognitive Maps of Socio Economic Model" Appl. Sci. Periodical, 225-27(2000).

[8] http://en.wikipedia.org/wiki/Fuzzy_clustering.

[9] A.Victor Devadoss, A.Rajkumar and C.Jayalatha, "Analysis of Individual faith through Holy Bible Using Fuzzy Clustering", IJCTE.2013.V5.785.

[10] A.Victor Devadoss, A.Rajkumar and Jose Parvin N Praveena, "A Study on Miracles through Holy Bible using Combined Overlap Fuzzy Cognitive Maps (COBFCMS), IJCA 53(15):17-21, 2012. 